\title{
ALGORITHM FOR CALCULATING THE NORMATIVE AREA OF AN INDUSTRIAL ENTERPRISE LAND PLOT
}

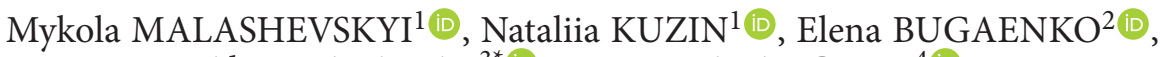 \\ Alena PALAMAR ${ }^{3} \mathbb{D}$, Mariia MALANCHUK ${ }^{4}$ (D) \\ ${ }^{1}$ Department of Land Management and Cadastre, Sumy Agrarian University, Sumy, Ukraine \\ ${ }^{2}$ Department of Land Management and Cadastre, Kyiv National University of Construction and \\ Architecture, Kyiv, Ukraine \\ ${ }^{3}$ Department of Geodesy, State Higher Educational Institution "Kryvyi Rih National University", \\ Kryvyi Rih, Ukraine \\ ${ }^{4}$ Department of Cadastre of Territory, Lviv Polytechnic National University, Lviv, Ukraine
}

Received 23 May 2018; accepted 11 June 2018

\begin{abstract}
In the article, the problem of finding justified approaches aimed at achieving sustainable development of urban land use is presented. In Ukraine, as in many post-Soviet countries of Eastern Europe, the transition to market relations has led to a change in production technologies, a reduction in the capacity or the termination of the functioning of industrial enterprises within settlements, but the parameters of land use remained unchanged. However, today, most of the especially large cities face the problem of lack of available land for its normal development. There are trends in the reduction of green zones and building compaction, etc.

Based on the results of the established sizes of normative land plots, tax regulation of land use it is proposed to levy a tax in a fivefold amount for a portion of the land plots granted to enterprises, institutions and organizations (except agricultural land) exceeding the standards of land allotment. In the case of the excess of establishing territory for enterprises, institutions and organizations and refusal to pay increased tax, it is possible to optimize the land use by means of an equivalent exchange.

Based on the results of the conducted studies it was established that when determining the area of a land plot for an industrial enterprise, the main technical characteristic is its capacity. Modelling is carried out on the basis of data on typical sizes of land plots and enterprise capacities.

It is established that a linear regression reliably approximates the dependence of the area on the capacity of the enterprise according to calculations. A detailed analysis shows that for low-capacity enterprises their area will be more reliably determined by non- linear dependence.
\end{abstract}

Keywords: modeling, linear approximation, least squares method, correlation dependence, regression equation, mean square error.

\section{Introduction}

In modern conditions, the problem of finding justified approaches aimed at achieving sustainable development of urban land use becomes extremely urgent. In Ukraine, as in many post-Soviet countries of Eastern Europe, the transition to market relations has led to a change in production technologies, a reduction in the capacity or the termination of the functioning of industrial enterprises within settlements, but the parameters of land use remained unchanged. However, today, most of the especially large cities face the problem of lack of available land for its normal development. There are trends in the reduction of green zones and building compaction, etc.

Thus, a promising direction is the spatial ordering of urban areas by rationalizing the land use of industrial enterprises. The optimization of urban space by redistributing land is proposed in (De Moor, 2015; Drees, 2002; Giovarelli \& Bledsoe, 2001). Thus there is a need to develop an approach that would allow to determine the excess land area of existing industrial enterprise.

${ }^{*}$ Corresponding author. E-mail: palamar1alena@gmail.com 


\section{Materials and methods}

Modeling the optimal ratio between the capacity of enterprise and its production facilities in determining the excess area

The definition of the normative area of industrial enterprise land plot is proposed to perform in the following order:

1. Selection of initial data, namely information on enterprises that use their territories rationally and efficiently and for their intended purpose and have project documentation produced in accordance with the requirements of the current legislation and contains a technical justification for the required area of the land plot;

2. Finding a mathematical model for determining the area of industrial enterprise land plot;

3. Accuracy assessment of the results.

Based on the results of the established sizes of normative land plots, tax regulation of land use it is proposed to levy a tax in a fivefold amount for a portion of the land plots granted to enterprises, institutions and organizations (except agricultural land) exceeding the standards of land allotment. In the case of the excess of establishing territory for enterprises, institutions and organizations and refusal to pay increased tax, it is possible to optimize the land use by means of an equivalent exchange (Malashevskyi \& Bugaienko, 2016).

Table 1. Typical sizes of land plots of Ukrainian bakery enterprises

\begin{tabular}{|c|c|}
\hline $\begin{array}{c}\text { Capacity of the enterprise, } \\
\text { tons/day }\end{array}$ & The land plot area, $\mathrm{m}^{2}$ \\
\hline 135 & 18000 \\
\hline 100 & 17000 \\
\hline 65 & 16000 \\
\hline 45 & 10000 \\
\hline 30 & 9000 \\
\hline 20 & 7000 \\
\hline $10-3$ & $5000-3000$ \\
\hline
\end{tabular}

\section{Linear approximation of the optimal ratio between the capacity of an enterprise and its production areas}

Based on the results of the conducted studies it was established that when determining the area of a land plot for an industrial enterprise, the main technical characteristic is its capacity (Malashevskyi \& Melnyk, 2016). Modeling is carried out on the basis of data on typical sizes of land plots and enterprise capacities. In this case, the objects of the food industry are considered due to lack of the need for further justification for the size of the warehouses area for storage of raw materials and finished products (Table 1) (Malashevskyi \& Gorpinich, 2014).

To determine the dependence of the land plot area $(y-$ variable) on the capacity ( $x$ - regressor) of the industrial enterprise, it is proposed to use the linear regression model:

$$
y=k_{1}+k_{2} x .
$$

To determine its parameters using the method of least squares, we use the following formulas:

$$
\begin{aligned}
& k_{2}=\frac{\sum_{i=1}^{n}\left(x_{i}-\bar{x}\right)\left(y_{i}-\bar{y}\right)}{\sum_{i=1}^{n}\left(x_{i}-\bar{x}\right)^{2}} ; \\
& k_{1}=\bar{y}-k_{2} \bar{x}
\end{aligned}
$$$$
-\sum_{i=1}^{n} x
$$

where $\bar{x}=\frac{i=1}{n}-$ is the selective average factor (enterprise capacity); $\bar{y}=\frac{\sum_{i=1}^{n} y_{i}}{n}-$ is the selective average of the indicator (the area of the land plot); $x_{i}, y_{i} i=1,2$, $\ldots, n$ - are the current values of the factor and indicator, respectively; $n$ - is the number of observations (sample size).

The initial data and the results of intermediate calculations are presented in Table 2.

Table 2. Estimation of linear regression parameters by least squares

\begin{tabular}{|c|c|c|c|c|c|c|c|c|c|c|}
\hline No & 1 & 2 & 3 & 4 & 5 & 6 & 7 & 8 & $\Sigma$ & Mean \\
\hline$X_{i}$ & 135 & 100 & 65 & 45 & 30 & 20 & 10 & 3 & 308 & 51 \\
\hline$Y_{i}$ & 18000 & 17000 & 16000 & 10000 & 9000 & 7000 & 5000 & 3000 & 68000 & 10625 \\
\hline$X_{i}-X_{\text {mean }}$ & 84 & 49 & 14 & -6 & -21 & -31 & -41 & -48 & 0 & 0 \\
\hline$Y_{i}-Y_{\text {mean }}$ & 7375 & 6375 & 5375 & -625 & -1625 & -3625 & -5625 & -7625 & 0 \\
\hline $\begin{array}{c}\left(X_{i}-X_{\text {mean }}\right)^{*} \\
\left(Y_{i}-Y_{\text {mean }}\right)\end{array}$ & 619500 & 312375 & 75250 & 3750 & 34125 & 112375 & 230625 & 366000 & 1754000 \\
\hline$\left(X_{i}-X_{\text {mean }}\right)^{2}$ & 7056 & 2401 & 196 & 36 & 441 & 961 & 1681 & 2304 & 15076 \\
\hline
\end{tabular}


Then, in accordance with the $k_{1}$ and $k_{2}$ defined by formulas (2) and (3) we obtain a linear regression model (1):

$$
y^{*}=4691.463+116.344 x .
$$

In order to assess the reliability of the correlation dependence between the capacity of the enterprise and its area, we perform the following calculations. Let's define the mean squared errors (Table 3 ):

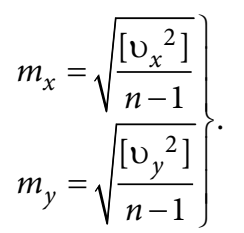

As a result, we obtain:

$$
\left.\begin{array}{l}
m_{x}=\sqrt{\frac{15076}{7}}=46.408 \\
m_{y}=\sqrt{\frac{229875000}{7}}=5730.557
\end{array}\right\} .
$$

The empirical correlation coefficient will be:

$$
\begin{aligned}
& r_{x y}=\frac{\left[v_{x} v_{y}\right]}{(n-1) m_{x} m_{y}} ; \\
& r_{x y}=\frac{1754000}{7 \times 46.408 \times 5730.557}=0.94 .
\end{aligned}
$$

The mean square error of the correlation coefficient is:

$$
\begin{aligned}
& m_{r}=\frac{1-r_{x y}^{2}}{\sqrt{n}} ; \\
& m_{r}=\frac{1-0.94^{2}}{\sqrt{8}}=0.040 .
\end{aligned}
$$

The presence of correlation dependence is determined by $r \geq t \cdot m_{t}$. With a confidence probability of $p=0.95$ from the tables of the Student's distribution for $n-1=7$, we get:

$0.77>2.36 \times 0.040$ or

$$
0.77>0.094 \text {. }
$$

To determine the functional relation between $x$ and $y$ we calculate the regression coefficient as follows:

$$
\begin{aligned}
\rho_{y / x} & =r_{x y} \frac{m_{y}}{m_{x}} ; \\
\rho_{y / x} & =0.94 \frac{5730.557}{46.408}=116.344 .
\end{aligned}
$$

Root-mean-square error of the regression coefficient:

$$
\begin{aligned}
& m_{\rho_{y / x}}=m_{r} \frac{m_{y}}{m_{x}} ; \\
& m_{\rho_{y / x}}=0.040 \frac{5730.557}{46.408}=4.901 .
\end{aligned}
$$

According to preliminary calculations, it is determined that the existing correlation dependence $r=0.94 \approx 1.0$, is approximated by straight-line function. Since the data are taken from the normative documents obtained from the results of experimental evaluations or from the available areas of existing industrial enterprises, they can be attributed to the technical measurements characterized by confidence at $p=0.90$. The regression coefficient by probabilistic analysis is sufficiently reliable at the assumed confidence level of $p=0.90$, since

$$
\begin{aligned}
& \rho_{y / x} \geq t_{\beta} m_{\rho_{y / x}} ; \\
& 116.344>9.313,
\end{aligned}
$$

\begin{tabular}{|c|c|c|c|c|c|c|}
\hline $\mathrm{X}$ & $\mathrm{y}$ & $v_{x}$ & $v_{y}$ & $v_{x} v_{y}$ & $v_{x}^{2}$ & $v_{y}^{2}$ \\
\hline 3 & 3000 & -48 & -7625 & 366000 & 2304 & 58140625 \\
\hline 10 & 5000 & -41 & -5625 & 230625 & 1681 & 31640625 \\
\hline 20 & 7000 & -31 & -3625 & 112375 & 961 & 13140625 \\
\hline 30 & 9000 & -21 & -1625 & 34125 & 441 & 2640625 \\
\hline 45 & 10000 & -6 & -625 & 3750 & 36 & 390625 \\
\hline 65 & 16000 & 14 & 5375 & 75250 & 196 & 28890625 \\
\hline 100 & 17000 & 49 & 6375 & 312375 & 2401 & 40640625 \\
\hline \multirow[t]{2}{*}{135} & 18000 & 84 & 7375 & 619500 & 7056 & 54390625 \\
\hline & & & & 1754000 & 15076 & 229875000 \\
\hline
\end{tabular}

where $t_{\beta}=1.90$ are determined from tables of the Student's distribution with confidence probability $p=0.90$ and $n-1=7$.

The regression equation is determined by the formula:

$$
y_{3}^{*}=\bar{y}-\rho_{y / x}\left(x_{i}-\bar{x}\right)
$$

or

$$
y_{i}^{*}=10625+116.344\left(x_{i}-51\right),
$$

i.e.

$$
y_{i}^{*}=4691.463+116.344 x_{i} .
$$

Table 3. Correlation 
Table 4. Estimation of the linear approximation accuracy

\begin{tabular}{|c|c|c|c|c|c|c|c|}
\hline No. & $x$ & $Y$ & $y^{*}$ & $v_{y^{*}}$ & $v_{y^{*}}^{2}$ & $y_{\min }^{*}$ & $y_{\text {max }}^{*}$ \\
\hline 1 & 3 & 3000 & 5040.5 & -2040.5 & 4163619.1 & 509.0 & 9572.0 \\
\hline 2 & 10 & 5000 & 5854.9 & -854.9 & 730857.1 & 1323.4 & 10386.4 \\
\hline 3 & 20 & 7000 & 7018.3 & -18.3 & 336.4 & 2486.9 & 11549.8 \\
\hline 4 & 30 & 9000 & 8181.8 & 818.2 & 669485.6 & 3650.3 & 12713.2 \\
\hline 5 & 45 & 10000 & 9926.9 & 73.1 & 5338.2 & 5395.5 & 14458.4 \\
\hline 6 & 65 & 16000 & 12253.8 & 3746.2 & 14033909.5 & 7722.3 & 16785.3 \\
\hline 7 & 100 & 17000 & 16325.8 & 674.2 & 454479.5 & 11794.4 & 20857.3 \\
\hline 8 & 135 & 18000 & 20397.9 & -2397.9 & 5749847.9 & 15866.4 & 24929.4 \\
\hline$\Sigma$ & & & & 0.0 & 25807873.4 & & \\
\hline
\end{tabular}

By regression Eq. (4), we calculate the value of the function, depending on the value of the enterprise capacity (Table 4).

Let's plot the regression dependence graph (Figure 1).

To estimate the accuracy of the approximation, let's determine the deviations of the calculated ordinates (Table 4):

$$
v_{y^{*}}=y-y^{*}
$$

and

$$
\left[u_{y^{*}}^{2}\right]=25807873 \text {. }
$$

Root-mean-square error of the regression:

$$
m_{y}=\sqrt{\frac{\left[\mathrm{u}_{\rho y / x^{2}}\right]}{n-1} ;}
$$

$$
m_{y}=\sqrt{\frac{25807873}{7}}=1920.11 .
$$

Extreme admissible deviation is defined as follows:

$$
\Delta_{\rho y / x}^{*}= \pm t_{\beta} m_{\rho_{y / x}}
$$

or

$$
\Delta_{\rho_{y / x}}^{*}=|2.36 \times 1920.11|=|4531.47| .
$$

Thus

$$
\begin{aligned}
& y_{i \text { min }}^{*}=y_{i}^{*}-4531.47 ; \\
& y_{i \text { max }}^{*}=y_{i}^{*}+4531.47 .
\end{aligned}
$$

According to Table 4 the maximum error of approximation is $v_{y^{*}}=+3746.2$.

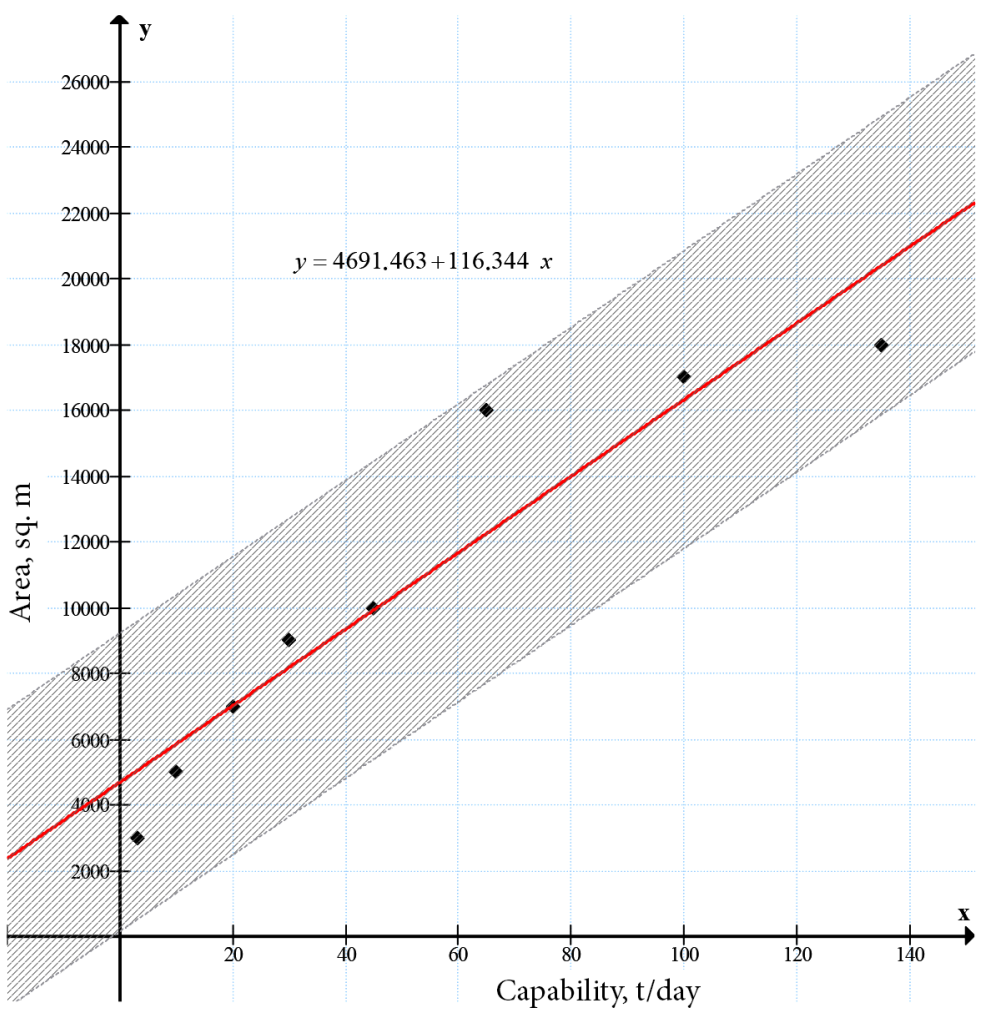

Figure 1. Graph of linear regression dependence 
Since $v_{y}<\Delta_{\rho_{y / x}}(+3746.2<4531.47)$, then the linear approximation of dependence of the area on the capacity of the enterprise is reliable. This is confirmed by the graph (Figure 1). By the extreme deviation $\pm \Delta_{\rho_{y / x}^{*}}^{*}$ let's construct the field of possible deviations of the areas depending on the capacity of enterprises according to Table 4 (Figure 1).

By calculations results, the equations of a straight line with the confidence intervals are obtained, from which it is possible to reasonably calculate the overstandard area of an industrial enterprise for further taxation or use for other more important problems of the local community.

It is established that a linear regression reliably approximates the dependence of the area on the capacity of the enterprise according to calculations. A detailed analysis of the graph (Figure 1) shows that for low-capacity enterprises their area will be more reliably determined by non- linear dependence.

\section{Parabolic approximation of the optimal ratio between the capacity of the enterprise and its production areas}

Let's calculate the correlation dependence of the $n$-th degree polynomial by the Chebyshev method. Let's assume the model of parabolic relation between the variables $x$ and $y$ express it as follows:

$$
y=k_{1}+k_{2} x+k_{3} x^{2}+k_{4} x^{3}+\ldots+k_{n} x^{n-1},
$$

where $n$ - is the exponent of the terms number in the expansion of the function, which is equal to the number of required parameters $k$ in the presence of reliable approximation.

The solution to the problem is to optimally determine the number of parameters $k$ of function (5) for $\left[p v^{2}\right]=\min$.

At the first stage, it is advisable to determine the approximate values of the parameters $k_{i}^{0}$. According to Table 2 we get:

$$
\left.\begin{array}{rl}
k_{2}^{0}= & \frac{\left(y_{n}-y_{1}\right)}{\left(x_{n}-x_{1}\right)}=\frac{1.5}{13.2}=+0.114 \\
k_{1}^{0}= & y_{0}-k_{2}^{0} x_{0}=0.971-0.114 \times 4.400=+0.470 \\
k_{3}^{0}= & \frac{\left(y_{0}-k_{1}^{0}-k_{2}^{0} x_{0}\right)}{x_{0}^{2}}= \\
& \frac{(0.971-0.470-0.114 \times 4.400)}{4.400^{2}}=-0.00005
\end{array}\right\},
$$

where $x_{0}=[x] / n ; y_{0}=[y] / n ; n-$ is the number of objects on which the dependency is defined.

The parametric correction equation for a parabola of the $n$-th degree is determined by the formula:

$$
\mathrm{U}_{3}=\tau_{1}+x_{i} \tau_{2}+x_{i}^{2} \tau_{3}+x_{i}^{3} K_{4}+\ldots+x_{i}^{n-1} K_{n}+l_{i},
$$

where $\tau_{i}=k_{i}-k_{i}^{0}$.

When calculating the coefficients of normal equations, it is convenient to reduce the value of $x_{i}$ (Table 5) by the formula:

$$
x_{i}=X_{i} \cdot 10^{-1} ; y_{i}=Y_{i} \cdot 10^{-4} \text {. }
$$

Let's define the system of normal equations from the recalculated coordinates of $\mathrm{x}_{\mathrm{i}}$ :

$$
\left.\begin{array}{l}
N_{11} \tau_{1}+N_{12} \tau_{2}+N_{13} \tau_{3}+N_{14} k_{4}+N_{15} k_{5}+L_{1}=0 \\
N_{21} \tau_{1}+N_{22} \tau_{2}+N_{23} \tau_{3}+N_{24} k_{4}+N_{25} k_{5}+L_{2}=0 \\
N_{31} \tau_{1}+N_{32} \tau_{2}+N_{33} \tau_{3}+N_{34} k_{4}+N_{35} k_{5}+L_{3}=0 \\
N_{41} \tau_{1}+N_{42} \tau_{2}+N_{43} \tau_{3}+N_{44} k_{4}+N_{45} k_{5}+L_{4}=0 \\
N_{51} \tau_{1}+N_{52} \tau_{2}+N_{53} \tau_{3}+N_{54} k_{4}+N_{55} k_{5}+L_{5}=0
\end{array}\right\},
$$

where $N_{11}=n ; N_{12}=[x] ; N_{13}=\left[x^{2}\right] ; N_{14}=\left[x^{3}\right] ; N_{22}=\left[x^{2}\right]$; $N_{23}=\left[x^{3}\right] ; N_{24}=\left[x^{4}\right] ; N_{34}=\left[x^{5}\right] ; N_{44}=\left[x^{6}\right] ; L_{1}=[l] ; L_{2}=$ $[x l] ; L_{3}=\left[x^{2} l\right] ; L_{4}=\left[x^{3} l\right]$.

The free terms of the parametric equations of corrections $l_{i}$ are calculated from:

$$
l_{i}=k_{1}^{0}+k_{2}^{0} x_{i}+k_{3}^{0} x_{i}^{2}-y_{i} .
$$

Table 5. Calculation of the normal equations coefficients

\begin{tabular}{|c|c|c|c|c|c|c|c|c|c|}
\hline & $\mathrm{x}^{\prime}$ & $\mathrm{y}$ & $x^{2}$ & $x^{3}$ & $x^{4}$ & $x^{5}$ & $x^{6}$ & $x^{7}$ & $x^{8}$ \\
\hline 1 & 0.3 & 0.3 & 0.090 & 0.027 & 0.008 & 0.002 & 0.001 & 0.000 & 0.000 \\
\hline 2 & 1 & 0.5 & 1.000 & 1.000 & 1.000 & 1.000 & 1.000 & 1.000 & 1.000 \\
\hline 3 & 2 & 0.7 & 4.000 & 8.000 & 16.000 & 32.000 & 64.000 & 128.000 & 256.000 \\
\hline 4 & 3 & 0.9 & 9.000 & 27.000 & 81.000 & 243.000 & 729.000 & 2187.000 & 6561.000 \\
\hline 5 & 4.5 & 1.0 & 20.250 & 91.125 & 410.063 & 1845.281 & 8303.766 & 37366.945 & 168151.254 \\
\hline 6 & 6.5 & 1.6 & 42.250 & 274.625 & 1785.063 & 11602.906 & 75418.891 & 490222.789 & 3186448.129 \\
\hline 7 & 10 & 1.7 & 100.000 & 1000.000 & 10000.000 & 100000.000 & 1000000.000 & 10000000.000 & 100000000.000 \\
\hline 8 & 13.5 & 1.8 & 182.250 & 2460.375 & 33215.063 & 448403.344 & 6053445.141 & 81721509.398 & 1103240376.879 \\
\hline$\Sigma$ & 40.8 & 8.5 & 358.840 & 3862.152 & 45508.196 & 562127.534 & 7137961.798 & 92251415.133 & 1206601794.262 \\
\hline$\Sigma / n$ & 5.829 & 1.214 & & & & & & & \\
\hline
\end{tabular}


Using the data in Table 5 and 6, we obtain a system of normal equations:

$$
\begin{aligned}
& 8 \tau_{1}+40.8 \tau_{2}+358.84 \tau_{3}+3862.15 k_{4}+ \\
& 45508.20 k_{5}-0.071=0 \\
& 358.84 \tau_{2}+3862.15 \tau_{3}+45508.20 k_{4}+ \\
& 562127.53 k_{5}-0.613=0 \\
& 508.20 \tau_{3}+562127.53 k_{4}+7137961.80 k_{5}+\text {. } \\
& 13.889=137961.80 k_{4}+ \\
& 92251415.13 k_{5}+341.644=0 \\
& 1206601794.26 k_{5}+5690.411=0
\end{aligned}
$$

At the first stage of approximation. we solve the normal equations for determining the parameters $k_{1}, k_{2}$, $k_{3}$. For this in the system of Eqs (7) we determine the coefficients $N_{11}, \ldots, N_{33}, L_{1}, L_{2}, L_{3}$. We solve the system of normal equations according to the Gaussian scheme and determine the corrections $\tau_{1}, \tau_{2}, \tau_{3}$.

To determine the number of approximation model parameters by the $n$-th degree parabola by the method of Chebyshev. the mean square errors mi and values $\left[\mathrm{v}^{2}\right]_{i}$ are calculated by the formulas:

$$
\begin{aligned}
& {\left[\mathrm{v}^{2}\right]_{2}=[l l]-\frac{L_{1}}{N_{11}} L_{1}-\frac{L_{2}^{(1)}}{N_{22}^{(1)}} L_{2}^{(1)} ;} \\
& {\left[\mathrm{v}^{2}\right]_{3}=\left[\mathrm{v}^{2}\right]_{2}-\frac{L_{3}^{(2)}}{N_{33}^{(2)}} L_{3}^{(2)} ;} \\
& {\left[\mathrm{v}^{2}\right]_{4}=\left[\mathrm{v}^{2}\right]_{3}-\frac{L_{4}^{(3)}}{N_{44}^{(3)}} L_{4}^{(3)} ;} \\
& m_{i}=\sqrt{\frac{\left[\mathrm{v}^{2}\right]_{i}}{n-i} .}
\end{aligned}
$$

As a result, the values: $\left[\mathrm{v}^{2}\right]_{2}=0.260, m_{2}=0.208$, $\left[\mathrm{v}^{2}\right]_{3}=0.053, m_{3}=0.117,\left[\mathrm{v}^{2}\right]_{4}=0.052, m_{4}=0.114,\left[\mathrm{v}^{2}\right]_{5}=$ $0.048, m_{3}=0.127$ were obtained.

Since for certain values the inequality:

$$
m_{5}>m_{4}
$$

is satisfied, then the calculations were completed by determining the corrections of five parameters.

As a result, the values of the corrections: $\tau_{3}=+0.026$; $\tau_{2}=+0.031 ; \tau_{1}=-0.175 ; k_{4}=-0.004, k_{5}=+0.0001$ are obtained.

Let's calculate the aligned values of the coefficients according to the following formula:

$$
k_{i}=k_{i}^{0}+\tau_{i} .
$$

Let's get the values:

$$
\begin{aligned}
& k_{1}=+0.470-0.175=+0.295 ; \\
& k_{2}=+0.114+0.031=+0.145 ; \\
& k_{3}=-0.00005+0.026=+0.026 ; \\
& k_{4}=-0.004 ; \\
& k_{5}=+0.0001 .
\end{aligned}
$$

According to (5) and (6) the equation of parabolic approximation (Figure 2) is:

$$
y=2952.969+144.917 x+2.604 x^{2}-0.0405 x^{3}+0.0001 x^{4} .
$$

In practical use of the model. an inequality:

$$
y_{i}-t m_{A} \leq y_{i}^{*} \leq y_{i}+t m_{A}
$$

is used.

Root-mean-square error of the approximation:

$$
m_{\grave{A}}=\sqrt{\frac{\left[\mathrm{v}^{2}\right]}{n-1}} .
$$

Then, according to the calculations given in Table 7 we obtain:

$$
m_{\grave{A}}=\sqrt{\frac{4811135.526}{7}}=829.039 .
$$

The field of permissible deviations of the enterprise areas is shown in Figure 2. Since with a confidence $p=0.9$ and $n-1=7$, in accordance with the Student's distribution $t_{\beta}=1.90$, then

$$
t_{\beta} m_{\Delta}=1.90 \times 829.039=1575.173 \mathrm{~m}^{2}
$$

Table 6. Calculation of coefficients $l_{i}$ and $L_{i}\left(k_{1}{ }^{0}=+0.470 ; k_{2}{ }^{0}=+0.114 ; k_{3}{ }^{0}=-0.00005\right)$

\begin{tabular}{|c|c|c|c|c|c|c|c|c|c|c|}
\hline$n$ & $k_{1}{ }^{0}$ & $k_{2}{ }^{0} x_{i}$ & $k_{3}{ }^{0} x_{i}{ }^{2}$ & $-y_{i}$ & $l_{i}$ & $l_{i} l_{i}$ & $x l$ & $X^{2} l$ & $x^{3} l$ & $X^{4} l$ \\
\hline 1 & 0.47 & 0.0342 & 0.000 & -0.3 & 0.204 & 0.042 & 0.061 & 0.018 & 0.006 & 0.002 \\
\hline 2 & 0.47 & 0.114 & 0.000 & -0.5 & 0.084 & 0.007 & 0.084 & 0.084 & 0.084 & 0.084 \\
\hline 3 & 0.47 & 0.228 & 0.000 & -0.7 & -0.002 & 0.000 & -0.004 & -0.007 & -0.014 & -0.029 \\
\hline 4 & 0.47 & 0.342 & 0.000 & -0.9 & -0.088 & 0.008 & -0.263 & -0.788 & -2.364 & -7.092 \\
\hline 5 & 0.47 & 0.513 & 0.001 & -1.0 & -0.016 & 0.000 & -0.072 & -0.324 & -1.457 & -6.556 \\
\hline 6 & 0.47 & 0.741 & 0.002 & -1.6 & -0.387 & 0.150 & -2.515 & -16.346 & -106.249 & -690.618 \\
\hline 7 & 0.47 & 1.14 & 0.005 & -1.7 & -0.085 & 0.007 & -0.850 & -8.500 & -85.000 & -850.000 \\
\hline 8 & 0.47 & 1.539 & 0.009 & -1.8 & 0.218 & 0.048 & 2.945 & 39.751 & 536.639 & 7244.620 \\
\hline$\Sigma$ & & & & & -0.071 & 0.261 & -0.613 & 13.889 & 341.644 & 5690.411 \\
\hline
\end{tabular}




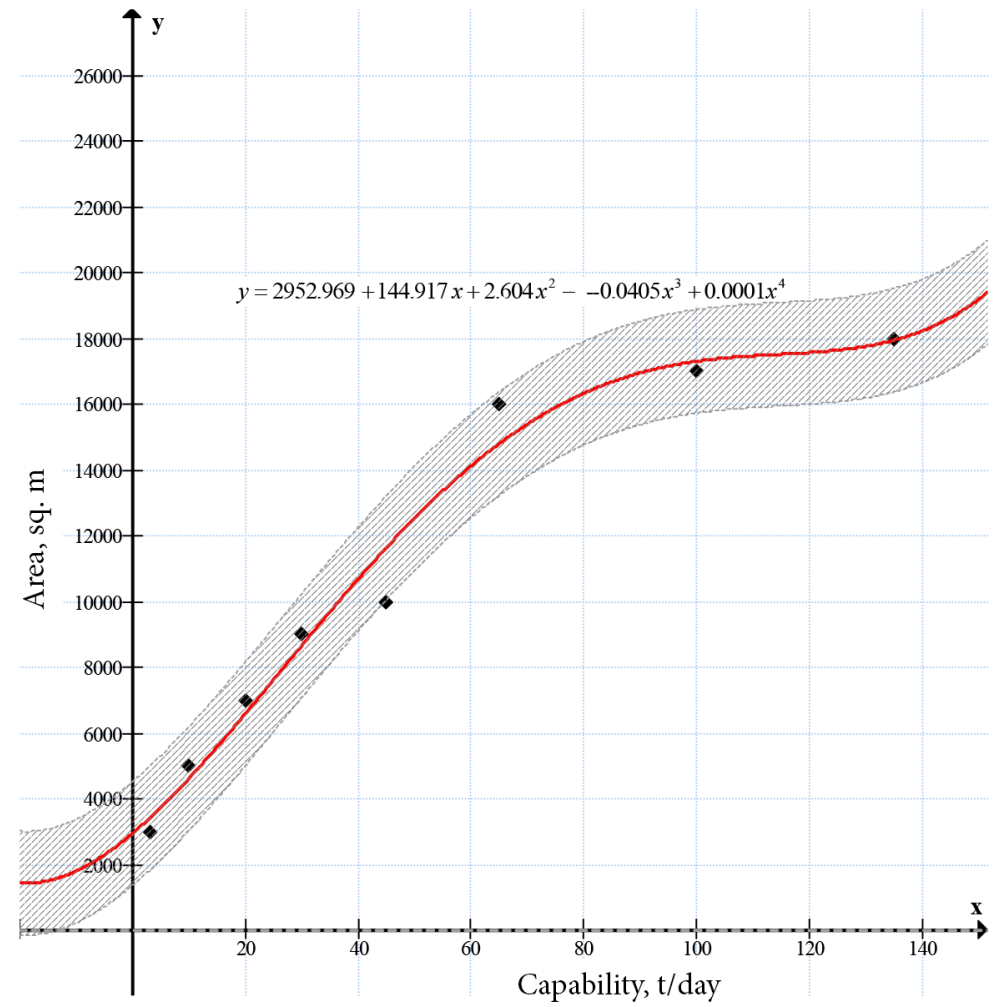

Figure 2. Graph of parabolic regression dependence

Table 7. Estimation of the approximation accuracy by the Chebyshev method

\begin{tabular}{|c|c|c|c|c|c|c|c|c|c|}
\hline No. & $X$ & $K_{1}$ & $K_{2} x$ & $K_{3} x^{2}$ & $k_{4} x^{3}$ & $k_{5} x^{4}$ & $y^{*}$ & $v_{y}{ }^{*}$ & $v_{y}{ }^{* 2}$ \\
\hline 1 & 3 & 2952.969 & 434.751 & 23.436 & -1.095 & 0.012 & 3410.073 & -410.073 & 168159.604 \\
\hline 2 & 10 & 2952.969 & 1449.169 & 260.397 & -40.544 & 1.437 & 4623.428 & 376.572 & 141806.502 \\
\hline 3 & 20 & 2952.969 & 2898.337 & 1041.587 & -324.350 & 22.992 & 6591.536 & 408.464 & 166843.197 \\
\hline 4 & 30 & 2952.969 & 4347.506 & 2343.570 & -1094.681 & 116.397 & 8665.762 & 334.238 & 111715.006 \\
\hline 5 & 45 & 2952.969 & 6521.258 & 5273.033 & -3694.547 & 589.261 & 11641.975 & -1641.975 & 2696083.117 \\
\hline 6 & 65 & 2952.969 & 9419.595 & 11001.761 & -11134.321 & 2565.142 & 14805.146 & 1194.854 & 1427675.293 \\
\hline 7 & 100 & 2952.969 & 14491.685 & 26039.671 & -40543.727 & 14370.038 & 17310.637 & -310.637 & 96495.073 \\
\hline 8 & 135 & 2952.969 & 19563.775 & 47457.300 & -99752.772 & 47730.171 & 17951.443 & 48.557 & 2357.735 \\
\hline$\Sigma$ & & & & & & & & 0.000 & 4811135.526 \\
\hline
\end{tabular}

\section{Conclusions}

Two models are proposed, which allow to determine the area of the land plot of an industrial enterprise, for which the norms of the land allotment, in fact, are exceeded.

The analysis of the mean square approximation errors of linear and parabolic model shows that the parabolic model more reliably determines the dependence of the area on the capacity of the enterprise and leads to a significant decrease in the field of permissible deviations of the area, which justifies the practical significance of the resulting parabolic model.

\section{Author Contributions}

Mykola Malashevskyi conceived the study and were responsible for the design and development of the data analysis. Natalia Kuzin and Maria Malanchuk were responsible for data collection and analysis. Elena Bugaenko and Alena Palamar were responsible for data interpretation.

\section{Disclosure Statement}

Authors have no competing financial, professional, or personal interests from other parties. 


\section{References}

De Moor, A. (2015). Urban Land Reallotment. In Geodesign. Summit Europe, 27-28 January 2015. Salzburg.

Drees, A. (2002, February). Challenges in East German States, in International Symposium "Land Fragmentation and Land Consolidation in CEEC: A gate towards sustainable rural development in the new millennium". Munich, Germany.

Giovarelli. R., \& Bledsoe, D. (2001). Land Reform in Eastern Europe. Western CIS, Transcaucuses. Balkans and EU Accession Countries. FAO. Seattle, Washington. Retrieved from http://www.fao.org/3/a-ad878e.pdf
Malashevskyi, M., \& Bugaienko, O. (2016). The substantiation of urban habitats peer land exchange in Ukraine. Geodesy and Cartography, 42(2), 53-57.

https://doi.org/10.3846/20296991.2016.1198568

Malashevskyi, M. A., \& Gorpinich. L. V. (2014). Pidkhody do vyznachennya nadnormatyvnykh ploshch pid promyslovymy obyektamy. Inzhenerna heodeziya, (60), 74-80 (in Ukrainian). Malashevskyi, M. A., \& Melnyk, L. V. (2016). The current state of taxation and regulation of land plot size of industrial areas in Ukraine. Mechanics, Materials Science \& Engineering, (3), 179-184. 